(RESEARCH ARTiCLE)

\title{
Tecno economics of LNG regasification terminal in Port Sudan
}

\author{
Ensaf Ali Alzbair* and Ahmad Elhusun \\ Department of chemical engineering, Karary University, Sudan.
}

World Journal of Advanced Engineering Technology and Sciences, 2021, 03(01), 023-033

Publication history: Received on 06 June 2021; revised on 01 August 2021; accepted on 03 August 2021

Article DOI: https://doi.org/10.30574/wjaets.2021.3.1.0052

\begin{abstract}
The main objective of this research is to select the appropriate regasification technology for Sudan liquefied natural gas (LNG) terminal at Portsudan, with a low Operating cost to suit the site climate conditions. Computer simulation software to design and simulate this technology to relize the optimum conditions which can regasify $352169 \mathrm{Kg} / \mathrm{hr}$ of $\mathrm{LNG}$ is used, where this quantity per year is the energy demand of Sudan, was calculated by the Port sudan power station.

Standard selection criteria were used to select the most suitable regasification technology. In this regard sea water vaporizer was found to be the best. Aspen HYSYS 10 was used for the simulation to design and determine the vaporizer specifications. Average monthly temperature and humidity data were used to run the simulation. Sea water consumptions in the vaporizer where $79880400 \mathrm{Kg} / \mathrm{hr}$. Design was implemented by using Aspen Exchanger Design and Rating program, where the optimum design of shell and tube evaporators were obtained.
\end{abstract}

Keywords: Natural gas; LNG regasification plant; Sea water; shell; Tube vaporizer

\section{Introduction}

Natural gas is a fossil fuel. This means it originates from the remains of plant and animals that lived many millions of years ago. These organisms were buried and exposed to heat as a result of being highly compressed underneath thousands of meters of soil and rock. These forces transformed the once living organisms into natural gas. It is found in reservoirs beneath the surface of the earth. Large layers of rock trap the natural gas as it tries to float to the surface. Although the areas where the gas is trapped are referred to as pools, the natural gas molecules are actually held in small holes and cracks throughout the rock formation [Alberta Energy 1995, About Natural Gas 1995.].

Natural gas is one of the cleanest and most useful forms of energy in our day lives. It is a hydrocarbon, which means it is made up of compounds of hydrogen and carbon. The simplest hydrocarbon is methan; and other hydrocarbons include ethane, propane, and butane. Water, oil, sulphur, carbon dioxid, nitrogen, and other impurities may be mixed with the gas when it comes out of the ground. These impurities are removed before the natural gas is delivered to our homes and businesses. Natural gas can be found by itself or in association with oil. It is both colorless and odorless and is in fact amixture of hydrocarbons. The fact that natural gas is combustible and burns more cleanly than some other energy sources help reinforce its position as one of the most highly used energy sources [ Anon 2015, Encana, 2015].

The liquid form of natural gas reduces the volume significantly, some impure non -methane components have been removed, It is transportable 1 more ideal way and also storable and can be kept in particular conditions and insulated tanks in order to be used in the future if immediately is not going to be used. As aconsequence, LNG trade continues to grow globally and is becoming the choice of countries as a fuel to provide the energy demands.

\footnotetext{
* Corresponding author: Ensaf Ali Alzbair

Department of chemical engineering, Karary University, Sudan. 
Regasification process is considered one of the most important and heart of the LNG terminal unit, and consumes more than half of the total operation cost. In that LNG import countries always interested to make process advanced and economical by doing more studies. Regasification process is process of converting a liquefied natural gas (LNG) at -162C $(-260 \mathrm{~F})$ temperature back to natural gas, where the temperature must be the temperature of send out gas (above $0 \mathrm{C})$.

There is different type of regasification, where available in world LNG terminal are:

- $\quad$ Open Rack Vaporizers (ORV).

- Submerged Combustion Vaporizers (SCV).

- Ambient Air Vaporizers (AAV).

- Intermediate Fluid Vaporizers (IFV).

Traditionally, base load regasification terminals have used two types of vaporizers: $70 \%$ uses the Open rack Vaporizer (ORV), $25 \%$ uses the submerged Combustion Vaporizer (SCV) and the remaining 5\% uses the Intermediate fluid vaporizer (IFV). In addition to these vaporizers, other types of vaporizers such as the direct air vaporizers, the Ambient Air Vaporizers (AAV), have been used in smaller regasification plants and peak shaving facilities. [1]

\subsection{Problem statement}

Vaporizing the LNG to its gaseous state using thermal energy sources controlled environment and therefor processing the gas in regasification plant and distributing is being done through different methods in industry. The selection of shell and tube vaporization unit has been done in order to be simulated and it is considered to be in pre -determined location to ponder the typical condition in the process.

\section{Objectives}

In the LNG terminal project, the regasification process is considered heart of the overall terminal process. The vaporizer selection is project specific and is typically selected on the basis of different criteria. The vaporizer must carefully the designed, as it has a major impact on operation costs. The main objective of this research is to select the appropriate regasification technology, which has a low Operating cost to suit Port sudan site conditions. Thereafter a simulation software would be used to simulate this technology to design and specify the optimum condition for operation at low operating cost.

\section{Literature Review}

\subsection{Worldwide natural gas consumption}

The worldwide liquefied natural gas (LNG) trade has increased steadily (over $5 \%$ per year) since the industry began with consumption increasing from 113.0 trillion cubic feet in 2010 to 185.0 trillion cubic feet in 2040. [2]

It is the fuel of choice for electric power and industrial sectors in many of the world's regions. In the reference case, total world consumption of natural gas for industrial uses increases by an average of 1.5 percent per year through 2040 and consumption in the electric power sector grows by 2.0 percent per year. The industrial and electric power sectors together account for 77 percent of the total projected increase in natural gas consumption and together they account for 74 percent of total natural gas consumption in 2040, up slightly from 73 percent in 2010.[3]

\subsection{Sudan energy consumption and plants for new source}

As the main source of energy, oil plays major role in the Sudanese economy, where power plants and most industrial sector depend completely on the refinery fuel product. Gasoline and diesel heart of transportation, and LPG for domestic consumption, where some produced in refinery and rest imported to satisfy the demand. Now oil production in Sudan is declining because of natural declines at maturing fields, and suffers severe financial crisis with the eminent demise of $75 \%$ of its oil revenues that represented over $90 \%$ of its foreign currency after the secession of its southern part after a constitutional referendum. Sudan has set ambitious goals to increase production continues to fall short of Sudan's goals because the demand of energy increased daily, another in 2012 a snapshot of the North Sudan macro - markets indicates the industrial production is negatively growing. [4] 


\subsection{LNG receiving terminal}

The receiving terminal is one component of the LNG chain between the gas field and the residential or industrial consumer. It is a facility atwhich liquefied natural gas is "regasified" (turned back into a gaseous state) after shipment by sea from the area of production. The receiving terminal can be onshore or offshore. Figure 1-3 shows a simplified schematic sketch of LNG receiving terminal. The main elementsare:

- $\quad$ Receiving LNG tankers and unloading their cargo.

- Storing LNG in cryogenic tanks to withstand temperatures below $-160^{\circ} \mathrm{C}$.

- $\quad$ Regasifying LNG to meet demand.

- $\quad$ Feeding gas into the national transmission network.

Figure 1 LNG Receveing Terminal

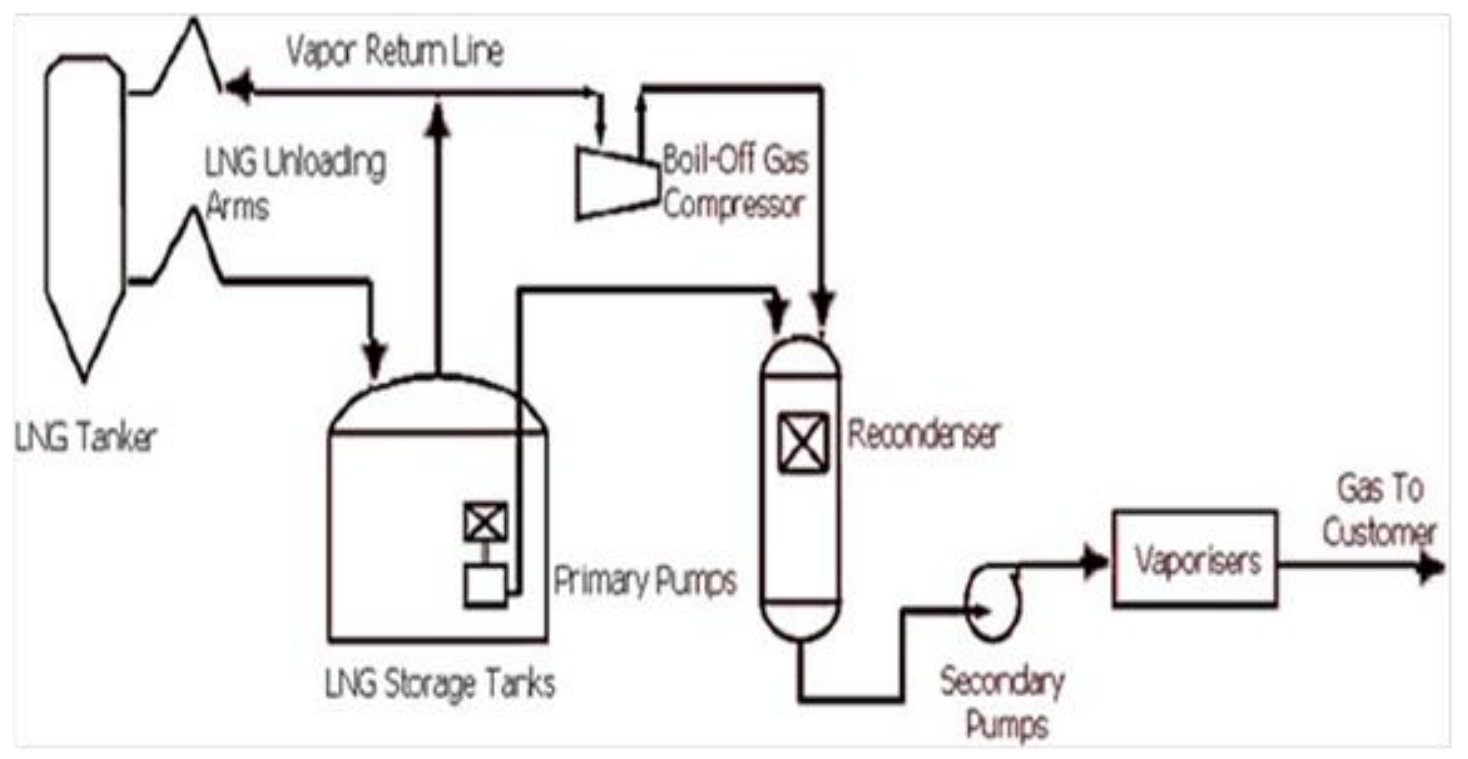

\section{Material and methods}

\subsection{Introduction}

Liquefied Natural Gas (LNG) is the liquid form of natural gas, the main component of which is methane.

In the liquefied form, at atmospheric pressure, LNG occupies only 1/600th of its volume at gaseous state under normal temperature and atmospheric pressure and, is therefore more economical to store and transport over long distances.

\subsection{LNG properties}

LNG is produced by cooling natural gas to $-162^{\circ} \mathrm{C}\left(-260^{\circ} \mathrm{F}\right)$ through a liquefaction process. Regasified LNG is clean burning, producing virtually no particulates and less NOx and $\mathrm{CO} 2$ than other fossil fuels. Since sulphur is almost entirely removed in the liquefaction process, combustion of regasified LNG emits negligible amounts of sulphur dioxide. [5] . LNG is stored at near atmospheric pressure, reducing the storage hazard compared with pressurized fuels (e.g. Liquefied Petroleum Gas-LPG). By warming LNG it vaporizes to become lighter than air and therefore rises when released. LNG is non-corrosive and non-toxic. LNG cannot ignite without first being vaporized, mixed with the right amount of air to result in a mixture of 5 to $15 \%$ methane in air, and provided with an ignition source. [5]

\subsection{Design Detials}

\subsubsection{Numrical Design Procedure}

Design shell and tube exchangers using Kern,s method assuming Over all coefficient ( U) and determine heat transfer area (A), start with one shell pass and two tube passes: 


$$
Q=U o \cdot A \cdot \Delta T_{m} .
$$

$Q=$ Heat transfer duty

$\Delta \boldsymbol{T}_{\boldsymbol{m}}=$ Mean temperature difference

Caculate tube size taking tube outer diameter (do) to be between 16 to $25 \mathrm{~mm}$ assuming $19.065 \mathrm{~mm}$, popular length (L) $=16 \mathrm{ft}=4.8762 \mathrm{~m}$.

$$
\begin{gathered}
\text { Area of one tube }=\pi d_{0} L \\
\text { Number of tubes } N t=\frac{\text { Estimated area }}{\text { Area of one tube }} \\
\text { Bundle diamter }\left(D_{b}\right)=d o\left(\frac{N_{t}}{K_{1}}\right)^{\frac{1}{n_{1}}}
\end{gathered}
$$

$\mathrm{K} 1, \mathrm{n} 1$ constant depend on tube pitch, assuming Triangular pitch.

Shell diameter (Ds) = Bundle diameter (Db) + clearance

Tube - side transfer coefficient (hi):-

$$
\begin{gathered}
\text { LNG mass velocity }=\frac{\text { LNG Flow }}{\text { Total Flow area }} \\
\text { LNG velocity }=\frac{L N G \text { mass velocity }}{\text { LNG Density }} \\
\frac{h_{i} d_{i}}{k_{f}}=j_{h} \cdot \operatorname{Re} P_{r}^{0.33}\left(\frac{\rho}{\rho w}\right)^{0.14}
\end{gathered}
$$

$\mathrm{di}=$

$\mathrm{Kf}=\mathrm{LNG}$ thermal conductivity.

$\operatorname{Re}=$ Reylonds number $=\rho$ ui $d / \mu$.

$\operatorname{Pr}=$ prantdil number $\mathrm{Cp} \mu / \mathrm{Kf}$

$\rho=$ LNG density.

$\rho w=$ Water density.

$\mathrm{Jh}=$ Heat transfer factor.

shell. Side heat transfer coefficient (ho ) :

Cross Flow area $\left(A_{s}\right)=\pi D_{s} l$

Shell side mass velocity Gs of the liner velocity $\mathrm{U}_{\mathrm{s}}$ : -

$$
G_{s}=\frac{W_{s}}{A_{s}}, u_{s}=\frac{G_{s}}{\delta}
$$

$w_{s}=$ fluid flow rate on the shell side,

For water Uw should be between $1.5-2.5$ 
$1.9 \mathrm{~m} / \mathrm{s}$ is acceptable.

Shell equivalent diameter (de) (hydraulic diameter):

$$
d_{e}=\frac{1.10}{d_{0}}\left(\rho_{t}^{2}-0.917 d_{0}^{2}\right)
$$

$h_{i}=\frac{4200(1.35+0.027) u^{0.8}}{d i^{0.2}}$ This is direct expression for heat transfer coefficient for water Over all heat transfer coefficient ( Uo )

$$
\frac{1}{. U O}=\frac{1}{h o}+\frac{1}{d h o}+\left(\frac{d o\left(I n\left(\frac{d o}{d i}\right)\right.}{2 k w}\right)+\frac{d o}{d i .} * \frac{1}{d i}+\left(\frac{d o}{d i}+\frac{1}{h i}\right)
$$

Where

Uo = over all heat transfer coefficient

ho $=$ heat transfer coefficient of shell

hi $=$ heat transfer coefficient of tube

dho $=$ fouling factor coefficient average of sea water

dhi $=$ fouling factor coefficient of $L N G$

$$
\text { Uo }=\frac{\text { Ucalculte }-U \text { assume }}{\text { Ucalculte }} * 100= \pm 30 \%
$$

\subsubsection{Sumlation design}

The simulation considers effect of temperature variation and mass flow of water in regasification process. Aspen Hysys is a process simulation environment designed to serve many processing industry especially Oil, Gas and Refining. With Aspen Hysys, one can create rigorous steady state and dynamic state models for plant design, performance monitoring, troubleshooting, operational improvement, business planning, and asset management.

The following steps are used in developing a steady state simulation model. In general, other software packages also follow similar approach for building the plant model.

- Selecting the unit set.

- Defining Simulation basis.

- Defining the feed streams.

- Installing and defining the unit operations like preheat exchangers, distillation columns.

- Installing the downstream unit operations.[6]

\section{Results and Analysis}

\subsection{Process description}

The LNG extracted from the storage tanks by means of the submerged pumps is pressurized initially to approximately 22 bar by the primary pumps (three in operation plus one in reserve) and, subsequently, to about 85 bar by the secondary pumps (three in operation plus one in reserve) and is then sent to the vaporizers. Each pump, both primary and secondary, has a maximum capacity of approximately $352169 \mathrm{~kg} / \mathrm{hr}$ of LNG The LNG is fed to shell \& tube heat exchanger where it is heated by (LNG inter in tube side and sea water in shell). $352169 \mathrm{~kg} / \mathrm{hr}$ is divided in two streams were entered to the first stage heat exchanger to reach stream temperature $-71^{\circ} \mathrm{C}$, then to second exchanger to reach stream temperature $-41^{\circ} \mathrm{Cand}$ to the third \& fourth one to reach it $-16^{\circ} \mathrm{C}$ till $7^{\circ} \mathrm{C}$ as all $\mathrm{LNG}$ at this condition in gas phase, the gas at $7^{\circ} \mathrm{C}$ send to main transmission pipeline for consumer. The cooled sea water flows into a sea where it is pumped to return back to the shell \& tube vaporizer. All the heat exchangers in shell and tube Vaporizer configuration are developed to have zero pressure drops in both shell and tube sides. There is an assumption of no heat loss in the heat exchangers which is considered as to be ideal. The simple BFD of the process has been shown below. 


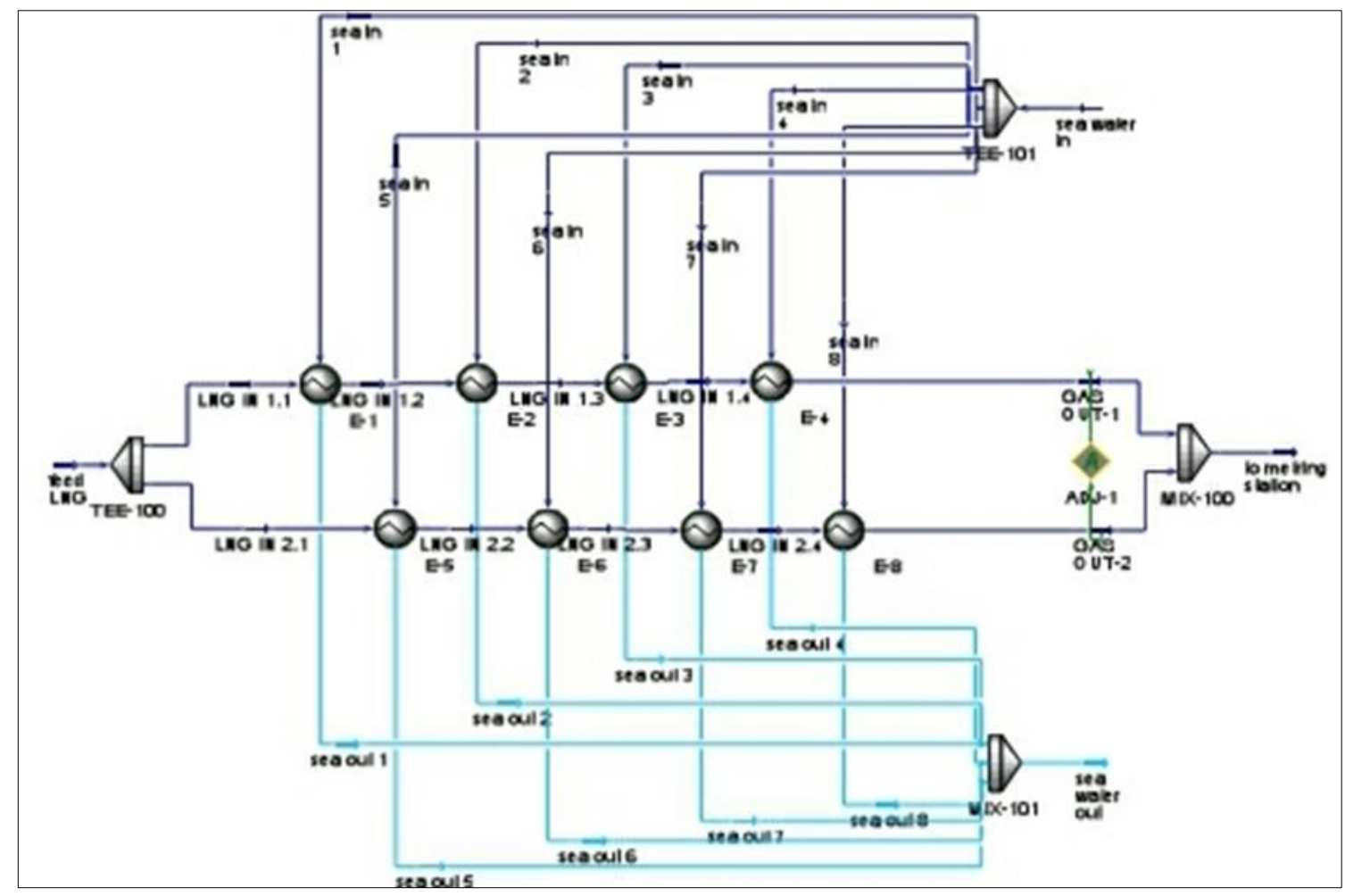

Figure 2 Process Flow diagram of LNG Vaporize

\subsection{Economics Estimation}

Table 1 Calculation of Total capital investment cost

\begin{tabular}{|c|c|c|}
\hline Component & Percent\% & Amount(\$) \\
\hline \multicolumn{3}{|l|}{ Direct cost } \\
\hline Total Equipment cost & \multicolumn{2}{|l|}{301480000} \\
\hline Electrical & $4.6 \%$ & 60559301 \\
\hline Buildings (including Services) & $4.6 \%$ & 60559301 \\
\hline Yard Improvements & $1.8 \%$ & 23697117 \\
\hline Service Facilities(installed) & $13.8 \%$ & 181677903 \\
\hline Land & $2 \%$ & 449.278 \\
\hline \multicolumn{3}{|l|}{ Total Direct Cost $=\$ 36,391,510$} \\
\hline \multicolumn{3}{|l|}{ Indirect Costs } \\
\hline Engineering and Supervision & $7.3 \%$ & 96104977 \\
\hline Construction Expense & $9.2 \%$ & 121118602 \\
\hline Contractor's Fee & $1.8 \%$ & 23697117 \\
\hline Contingency & $7.3 \%$ & 96104977 \\
\hline Working capital & \multicolumn{2}{|c|}{$10 \%$ from the total capital investment } \\
\hline
\end{tabular}


Chemical plant are built to make a profit and an estimate of the investment required and the cost of production are needed before the profitability of a project can be assessed. An acceptable design must present a process that is capable of operating under conditions which will yield profit .Capital must be allocated for the direct plant expenses such as those for raw material, labor and equipment. Besides direct expenses many other indirect expenses are also incurred e.g. a administration, salaries, product distribution cost, cost for interplant communication.

\subsection{Cash flow Diagram}

A cash flow diagram, such as that shown in Figure below, shows the forecast cumulative netcash flow over the life of a project. The cash flows are based on the best estimates of investment, operating costs, sales volume, and sales price that can be made for the project.

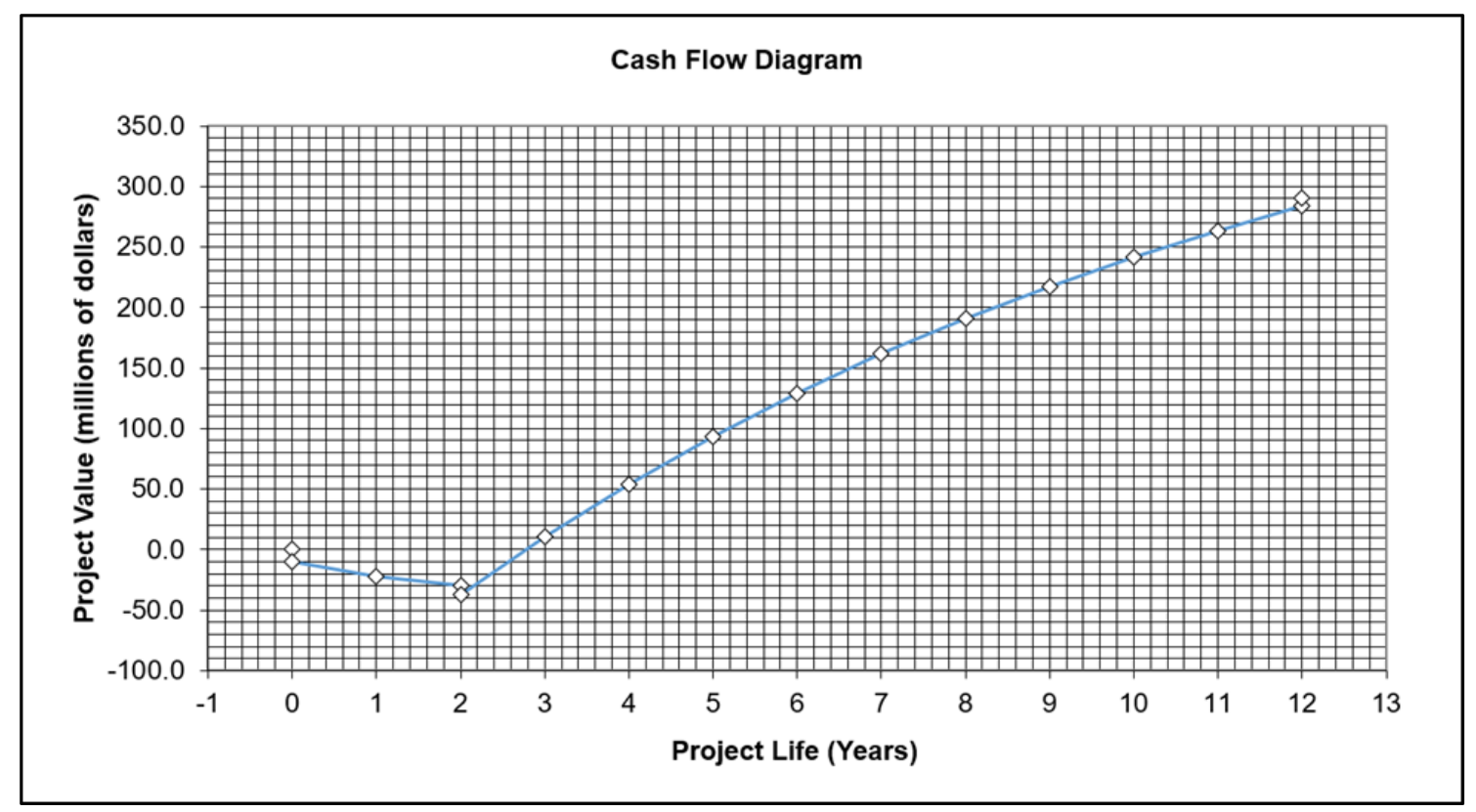

Figure 3 Cash flow diagram

\subsection{Summary of Cost Estimation}

Table 2 Summary of cost estimation

\begin{tabular}{|l|l|}
\hline Fixed cost investment & $\$ 929164118$ \\
\hline Working capital & $\$ 163970138$ \\
\hline Total cost investment & $\$ 1083134256$ \\
\hline Deprecation & $\$ 20098666$ \\
\hline Total production cost & $\$ 733197378$ \\
\hline Cost per unit & $\$ 338$ \\
\hline Selling price & $\$ 600$ \\
\hline IRR & $43.6 \%$ \\
\hline Pay back & $2.3 y e a r s$ \\
\hline
\end{tabular}




\subsection{Numirical design}

Table 3 The design calculations are summarized in table below

\begin{tabular}{|c|c|c|}
\hline Shell side fluid & Sea Water & - \\
\hline Tube side fluid & LNG & - \\
\hline Flowrate for shell side & 75916800 & $\mathrm{Kg} / \mathrm{hr}$ \\
\hline Flowrate for tube side & 301667.26 & $\mathrm{Kg} / \mathrm{hr}$ \\
\hline Fouling factor in shell & 0.00065 & $\left(\mathrm{~W} / m^{2} \cdot{ }^{\circ} \mathrm{c}\right)^{\wedge}-1$ \\
\hline Fouling factor in tube & 0.0002 & $\left(\mathrm{~W} / m^{2} \cdot{ }^{\circ} \mathrm{c}\right)^{\wedge}-1$ \\
\hline Temperature in (shell side) & 25 & ${ }^{\circ} \mathrm{C}$ \\
\hline Temperature out (shell side) & 15 & ${ }^{\circ} \mathrm{C}$ \\
\hline Temperature in (tube side) & -162 & $\circ \mathrm{C}$ \\
\hline Temperature out (tube side) & 7 & ${ }^{\circ} \mathrm{C}$ \\
\hline Required duty & 855696.8 & kw \\
\hline Heat transfer area & 33.75 & $m^{2}$ \\
\hline Tube side heat transfer coefficient & 1624.07 & $\mathrm{~W} / \mathrm{m}^{2} \cdot{ }^{\circ} \mathrm{C}$ \\
\hline Shell side heat transfer coefficient & 7822.6 & $\mathrm{~W} / \mathrm{m}^{2} \cdot{ }^{\circ} \mathrm{C}$ \\
\hline Overall heat transfer coefficient & 703.4 & $\mathrm{~W} / \mathrm{m}^{2} \cdot{ }^{\circ} \mathrm{C}$ \\
\hline Tube Outer diameter & 0.02 & $\mathrm{~m}$ \\
\hline Tube Internal diameter & 0.016 & $\mathrm{~m}$ \\
\hline Tube length & 3.657 & $\mathrm{~m}$ \\
\hline Tube pitch & 0.028 & $\mathrm{~m}$ \\
\hline Number of tubes & 156 & tubes \\
\hline Number of shell and the passes & 1-shell2-tubepasses & \\
\hline
\end{tabular}

\subsection{Simulation Analysis}

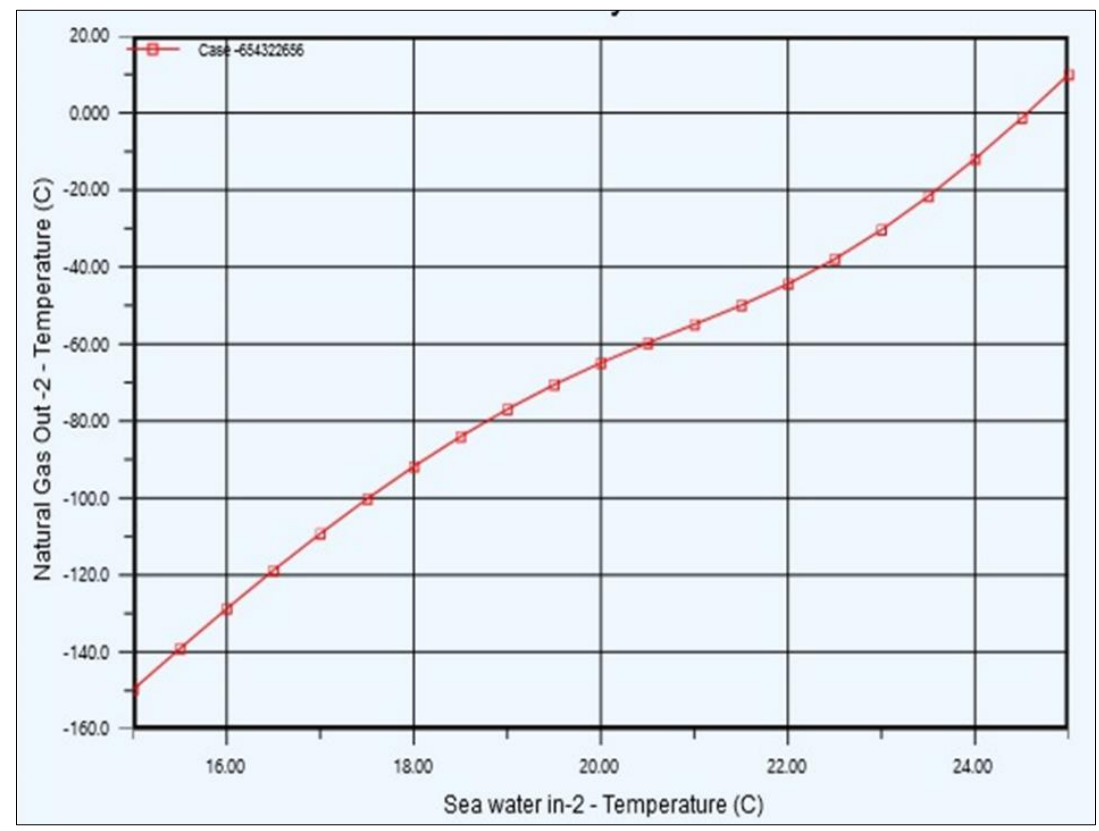

Figure 4 Effect of sea water Temperature in Natural Gas Temperature 
World Journal of Advanced Engineering Technology and Sciences, 2021, 03(01), 023-033

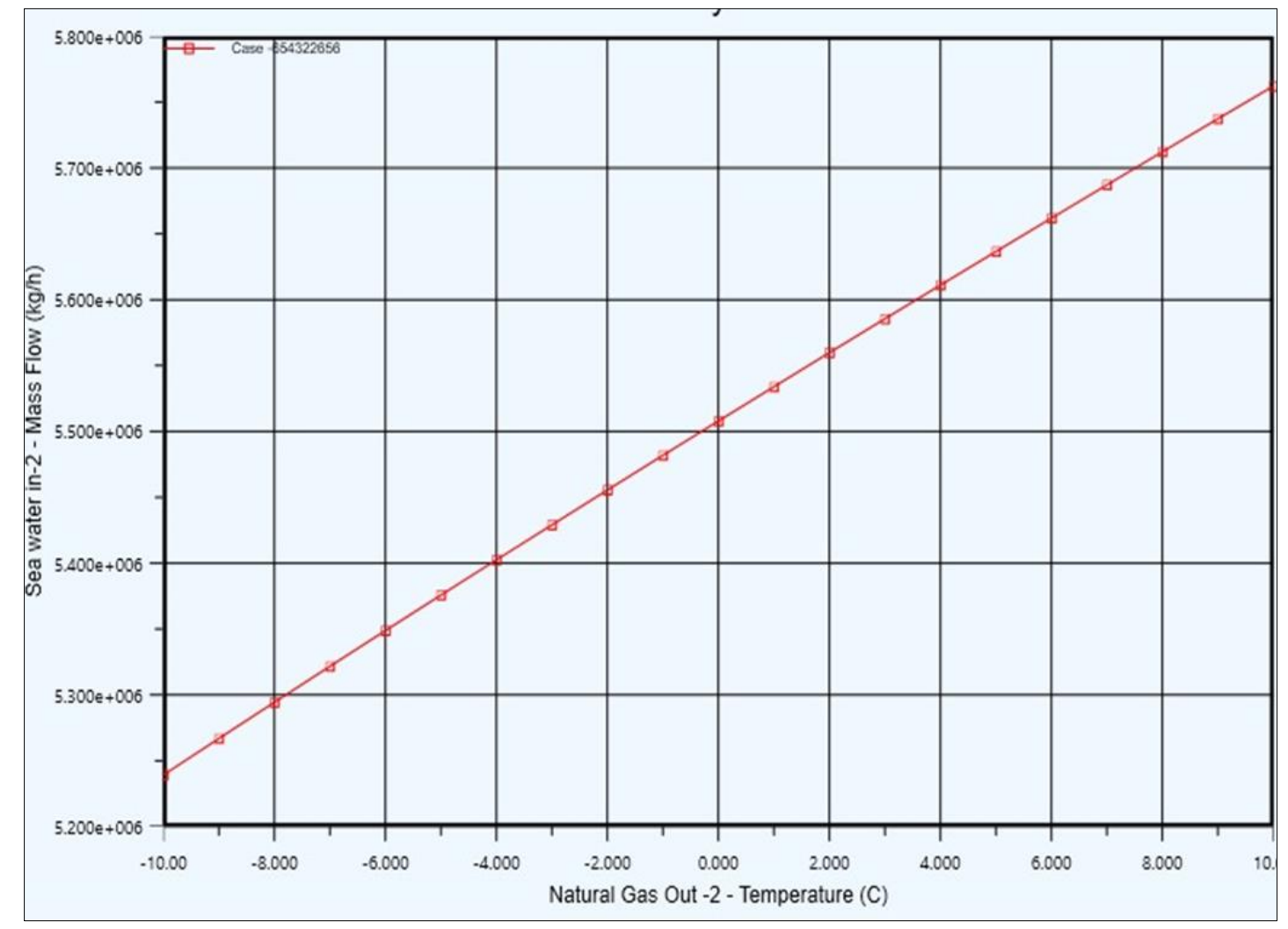

Figure 5 Effect of sea water mass flow in Natural Gas Temperature

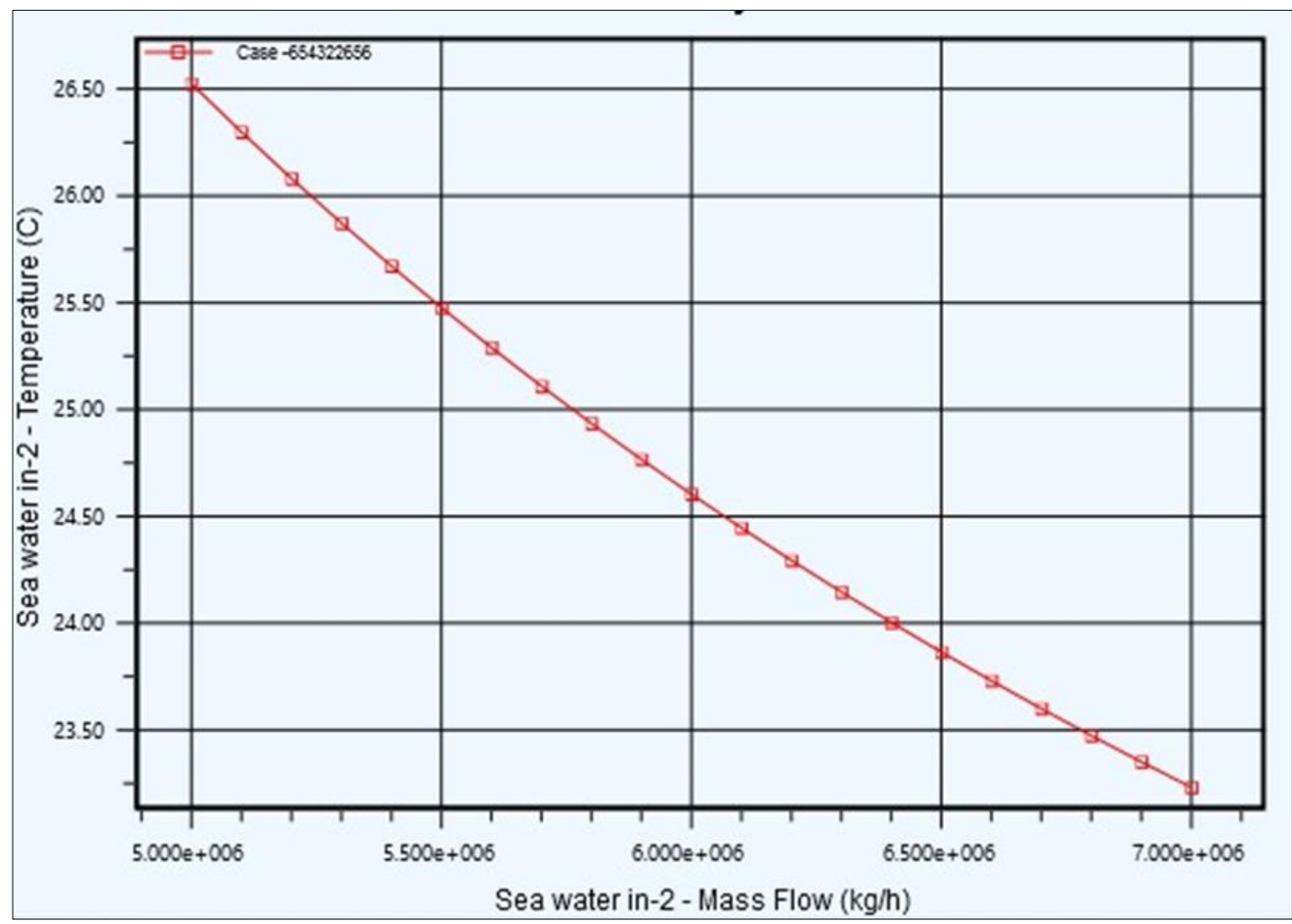

Figure 6 Effect of sea water mass flow in sea water in temperature 


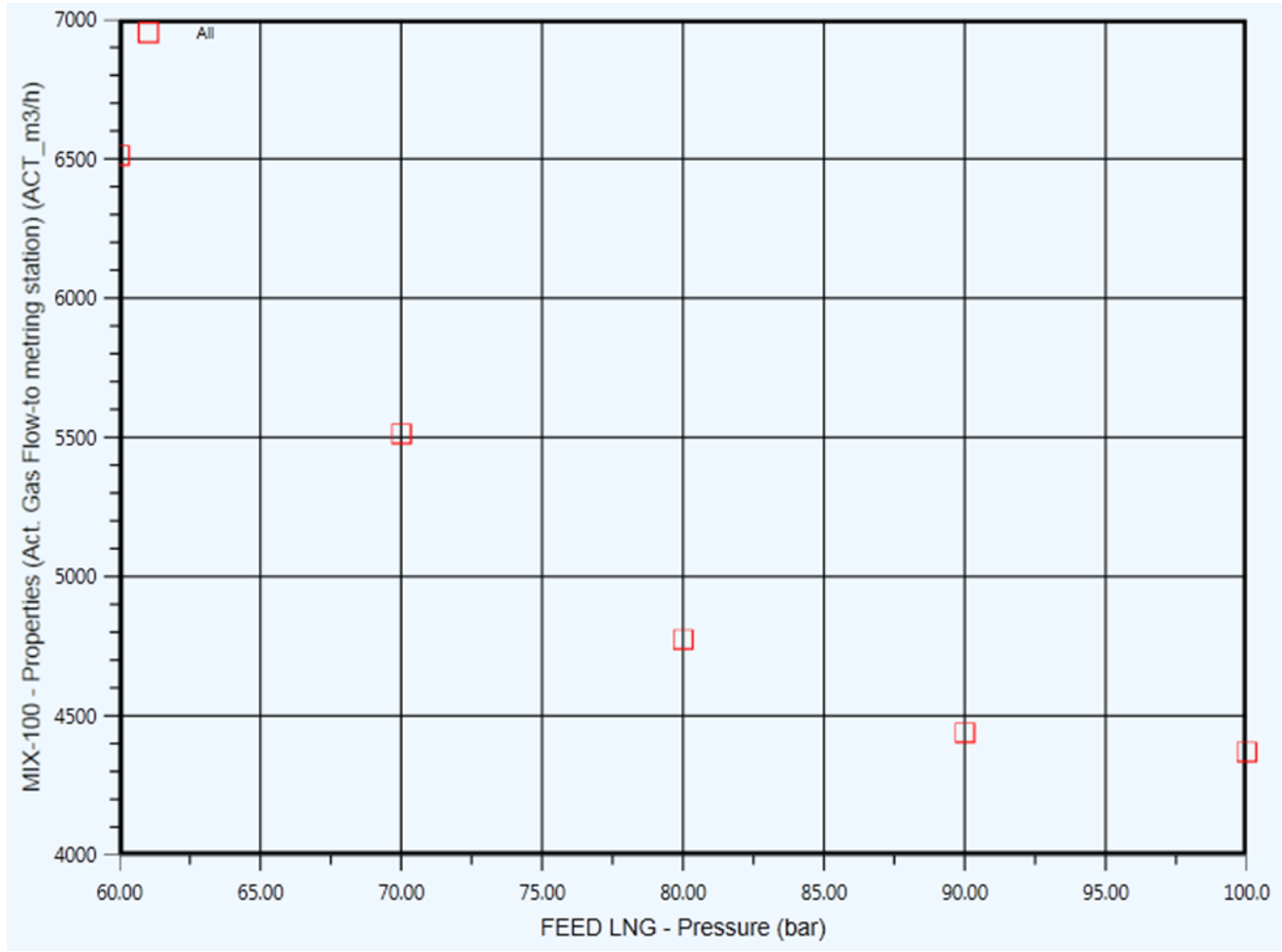

Figure 7 Effect LNG feed pressure in Nutral Gas flow in metering

\section{Conclusion}

The following are the conclusions drawn from this research work:

- According to standard criteria used to select an optimal regasification technology, the use of Sea water heating is considered the most desirable, where the intermediate Sea water vaporizer is the best choice between the other technologies.

- The technology was simulated by Aspen HYSYS 10 simulation, where the effect of average monthly temperature and humidity variation was studied.

- Aspen Exchanger Design \& Rating was used to design eight Shell and Tube heat exchangers, where the optimum design was obtained, and the was the amount of water is consider in the design.

\section{Compliance with ethical standards}

\section{Acknowledgements}

I would like to thank my research advisor, Professor: Ahmed Elhassan for his patience, guidance and support over the course of this research. I will always be indebted to him. He was a constant inspiration, and his assistance and suggestions were very helpful towards the completion of this work. I would also like to thank the members of my exam committee, for their efforts in reviewing and evaluating my research.

\section{Disclosure of conflict of interest}

About the disclosure of conflict of interest, we don't need to add, because the authors are just one in addition to the also one of the coauthors. 


\section{References}

[1] Michael F, Justine L. Barden, 2013. Energy Information Administration. International Energy Outlook 2013, 5,53

[2] JungHan L, Hochung K, (2005). Design and Construction of LNG Regasification Vessel. In Gastech. Bilbao, Spain, 14 Marchr13. South Korean: Daewoo Shipbuilding \& Marine Engineering Co. Ltd..3.

[3] John Mak, F, (2013). LNG Vaporizer Selection Based on Site Ambient Conditions . In Gas Processors Association Europe. Edinburgh, 29 September13. Edinburgh: GPA Membership. 14.

[4] Shaw Consultants International, I., 2012. CURACAO CNG- LNG TERMINAL FEASIBILITY STUDY, Netherlands: World of Solutions.

[5] Durr, C., (2005). LNG IMPORT TERMINALS RECENT DEVELOPMENTS, United Kingdom: M. W. Kellogg Ltd.

[6] Aspen Technology, Inc., 2011. Aspen HYSYS Unit Operations Guide. V7.3 ed. USA: Burlington 